\title{
Erratum to: Tubal Precursor Lesions in High Grade Serous Ovarian Carcinoma
}

Mahmoud Hanafy Meleis ${ }^{1}$ - Amany Abdelbary Abdellatif ${ }^{2}$. Ahmed Mohammed Samy El-Agwany ${ }^{1}$

Published online: 21 March 2016

(C) Association of Gynecologic Oncologists of India 2016

\section{Erratum to: Indian J Gynecol Oncolog DOI 10.1007/s40944-015-0031-3}

We, the authors, agree to the following changes on our manuscript (DOI 10.1007/s40944-015-0031-3) entitled (Tubal Precursor Lesions for High-Grade Serous Ovarian Carcinoma) regarding title and authors.

The online version of the original article can be found under doi:10. 1007/s40944-015-0031-3.

Ahmed Mohammed Samy El-Agwany

Ahmedsamyagwany@gmail.com;

ahmed.elagwany@alexmed.edu.eg

1 Department of Obstetrics and Gynecology, El-Shatby Maternity University Hospital, Faculty of Medicine, Alexandria University, Alexandria, Egypt

2 Department of Pathology, Faculty of Medicine, Alexandria University, Alexandria, Egypt 